Frontiers: The Interdisciplinary Journal of Study Abroad

(C) 2021 Jacie Grant, Kris Acheson, and Elizabeth Karcher

The work is licensed under the Creative Commons Attribution-NonCommercial-NoDerivatives

4.0 International License.

Volume 33, Issue 1, pp. 129-147

DOI 10.36366/frontiers.v33i1.491

FORUM

ON EDUCATION

ABROAD

\title{
Using the BEVI to Assess Individual Experience to Enhance International Programming
}

\author{
Jacie Grant ${ }^{1}$, Kris Acheson ${ }^{1}$, Elizabeth L. Karcher ${ }^{1}$
}

\begin{abstract}
Success in diverse educational and work environments requires intercultural competence, positive attitudes towards difference, and willingness to interact across cultures. Consequently, study abroad participation has increased as universities aim to internationalize; yet we lack clear evidence of study abroad providing students with skills and attitudes the programs intend to develop. This case study $(n=10)$ documents with a mixed methods tool the changes in student attitudinal data after participation in a semester long course with incorporated intercultural learning activities and a 9-day trip to Vietnam. Researchers anticipated positive development in critical thinking, openness, and environmental concern measured by the Beliefs, Events, and Values Inventory (BEVI). Overall, the average group scores did not increase; however, in a more detailed analysis, interesting patterns emerged within the data regarding unintended learning outcomes and variation in the data reflective of individual differences in identity and preparedness for learning. The findings illustrate how quantitative methods can function even with a small $\mathrm{N}$, demonstrate the importance of synthesizing formative and summative assessment practices, and suggest potential curriculum changes and additional resources to support student needs.
\end{abstract}

\section{Keywords:}

BEVI, Intercultural Competence, Student Development, Study Abroad, Assessment

\section{Introduction}

In the $21^{\text {st }}$ century, workplace and educational environments have been shaped by demographic, technological, and social changes (Stringfield \& Stone, 2017). There is increased diversification; populations are increasing, and lifespans are lengthening. Rapid

1 Purdue University, West Lafayette, IN, USA

Corresponding author: Elizabeth L. Karcher, ekarcher@purdue.edu 
and continuous globalization prompts collaboration across cultures now more than ever. There are currently five generations that comprise the workforce and $57 \%$ of women contribute to labor forces, indicating diversity's multiple facets, including by gender and age (USDOL, 2017). These components of the evolving social environment require current graduates to develop skills beyond the technical realm; they must be prepared to respond to and lead throughout social unrest and global challenges such as those that have abounded during 2020. "Global citizens" is a common phrase used to indicate the type of graduates universities aim to produce. Despite the multitude of definitions explaining the term (Byker \& Putman, 2019), Lilley et al. (2017) determined that an absolute definition for global citizen is unnecessary because there is consistency between what skills, attitudes, and knowledge are attributed to such individuals. Those common components included openness and tolerance, accountability of oneself, others, and the environment, and maintaining respect for differences (Lilley et al., 2017).

Familiar competencies relating to global citizenship are those such as cultural selfawareness, awareness of others, and intercultural communication skills. As universities prepare students for their careers, personal and interpersonal skills as well as globalmindedness are fundamental. These skills have never been more imperative than in the current moment when, within the workplace and society in the US, we find ourselves both at a pivotal point in the pursuit of racial justice and in desperate need of solutions to the negative impacts of a global pandemic. Some higher education institutions have implemented campus-wide learning outcomes of intercultural competence and global consciousness for all undergraduate students (Purdue University Office of the Provost, 2019; University of Illinois Office of the Provost, 2019). However, assessment of learning outcomes is necessary to demonstrate their achievement. Internationalization in higher education is a relatively new field of study, emerging in the 1990s (Bedenlier et al., 2018). Although universities are pursuing global learning in order to infuse global concepts, there needs to be a continued evolvement of the approaches to attain these goals (Kahn \& Agnew, 2017).

One way in which universities aim to internationalize is through the use of study abroad (SA) programming. Mawer (2017) highlights the increased funding provided for international scholarships to promote this type of student learning. SA opportunities are widely encouraged due to the potential of providing students with engagement in global practices, prompting the development of competencies (Vande Berg et al., 2012). However, development does not simply correspond with experience abroad (Passarelli \& Kolb, 2012). This is where assessment plays an important role. While students are credited with accomplishing major and minor requirements, the more advantageous rewards of SA include the development of knowledge, skills, and attitudes around internationalization (Wandschneider et al., 2015).

Much research analyzes development and experience at the cohort level, but assessing individual learners is equally important (Wandschneider et al., 2015). These researchers highlight the importance of understanding who learners are before an experience in order to both evaluate changes over time effectively and tailor curriculum to learner needs. Common assessment tools to measure the effectiveness of internationalization efforts and students' intercultural competence development include the Intercultural Development Inventory (IDI), Global Perspectives Inventory (GPI), and The Global Mindedness Scale (GMS) (Roy et al., 2014). The Beliefs Events and Values Inventory (BEVI) is another empirically validated tool used to evaluate group changes over 
time, individual and cohort trends, and event impact on subgroups with different social identities (Iseminger, Acheson, Kelly, \& Morris, 2020).

Assessment, both formative and summative, is a critical component of SA program evaluation (Roy et al., 2014). While formative assessments are strategically placed throughout courses to evaluate the variances within student learning and to improve teaching methodologies at periodic time points, summative assessment evaluates the holistic effect on learning outcomes at the end of a program (Dixson \& Worrell, 2016). An important formative assessment utilized in SA programming is critical reflection (Savicki et al., 2015). Responses to this type of formative assessment should assist educators in adjusting curriculum as necessary to meet student needs. Without intermittent evaluation, there are missed opportunities to adjust throughout programming. Formative and summative assessment should be used in conjunction with one another for complete evaluation in the classroom (Dixson \& Worrell, 2016). In this study, the BEVI is utilized for both formative and summative assessment while reflective prompts serve as additional formative assessments throughout the semester. Note that the scope of the current paper is limited to the BEVI quantitative and qualitative data alone and does not incorporate analysis of other written reflections from the course because of space considerations.

This SA program, while focused on agricultural disciplines within Vietnam, aimed to expose students to agriculture on a global scale and raise awareness to the importance of intercultural competence development. The BEVI (2018) is a widely used and validated tool that facilitates growth, addresses organizational needs, and evaluates learning in multicultural programs. This study collected preliminary data using a novel assessment tool and is utilized as a case study to evaluate areas of opportunity in international program development and curriculum design.

\section{Theoretical Framework}

It is clear from the scholarship of teaching and learning that, when it comes to progressing on intercultural and other types of learning outcomes assessment for participants in a course or other educational intervention, pedagogy, and program design matter (Krishnan et al., 2017). In fact, a team of experts recently outlined 15 implications of a learning outcomes meta-analysis using the BEVI, arguing that program design and implementation are two of the seven most impactful factors for transformative learning in international education (Wandschneider, et al., 2015).

Transformative Learning (TL) theory, originally developed by Mezirow (1978) as an application of Freire's (1970) work to female non-traditional community college students, has recently gained traction as a framework for discourse in U.S. tertiary education. Transformative learning refers to both the processes and outcomes of particular kinds of learning experiences in which the learner's sense of self, of being in the world, and relationships with others are profoundly called into question (Acheson et al., in press). Hoggan (2016) identified a typology of six facets of transformation, including worldview, self, epistemology, ontology, behavior, and capacity. TL theory is especially popular in reference to high impact learning experiences (Kuh, 2008) such as study abroad, international service learning and practice, and learning communities. However, scholars and practitioners interested in such experiences that seem to have a profound effect on an adult's sense of self and relationships to the broader world are confronted with the problem of assessment. Despite decades of important theoretical work on TL theory and its 
applications to myriad contexts (Cranton \& Taylor, 2012), the discipline has struggled to operationalize TL theory in such a way that transformative outcomes can be effectively documented. Recently, the BEVI has been used to operationalize TL theory (Acheson, Dirkx, \& Shealy, 2020).

Another theory contributing to the theoretical framework of the current project is Equilintegration (EI) theory. EI theory integrates findings from centuries of scholarly literature in various disciplines including psychology, philosophy, and education relevant to the constructs of the self, human needs, and beliefs. In synthesizing these constructs, EI theory seeks to explain the relationship between developmental, socio-cultural, and demographic variables and how the systems of beliefs and values that make up the self, come to be, explicating "the processes by which beliefs, values, and worldviews are acquired and maintained, why their alteration is typically resisted, and how and under what circumstances their modification occurs" (Shealy, 2004, p. 1075). This theory provides a critical link in understanding learner development because it makes visible the what that transforms as a result of educational experiences, that is, the structures of the self that changes. Layering EI theory onto TL theory is helpful because it highlights the relative preparedness (or lack thereof) of learners for transformation, and thus is able to predict their engagement in processes of transformative learning. EI theory focuses us on human needs, and in doing so enriches our understanding of both how and why transformative learning occurs, or does not occur (Acheson, Dirkx, \& Shealy, 2020). Both theories were selected for this study because they allow for a better identification and understanding of the transformative course experience and provide a context for the student experience.

\section{Purpose and Objectives}

The purpose of this study is to explore and describe student development in a semester program including an international component. The objectives include assessing student BEVI results at two different time points 1) week 1 of the semester (T1) and 2) after the completion of a 16-week semester course with an embedded 9-day study abroad to Vietnam (T2) and noting the changes between the two points. Analysis of T1 data provides important information to instructors about students' preparedness to engage in intercultural learning. Perhaps more importantly, sharing and reflecting on T1 data with students themselves before the travel component provides an opportunity for predeparture development of self-awareness. Finally, exploring changes throughout the semester allows researchers to note areas of strength and weakness in the curriculum design and structure of the program.

\section{Materials and Methods}

\section{Course Design}

This IRB approved study of a semester long course, including a 9-day SA to Vietnam, was designed for use at a large midwestern, land-grant university in the spring of 2018. The study population consisted of eleven undergraduate students who self-selected to enroll in the course to study food security and environmental challenges faced by Vietnamese agriculture. Students were recruited by advertising information about the course through college-wide emails and visiting large classes across the college to discuss the opportunity. Teaching methodologies aimed to address aspects of intercultural competence were implemented into the course design. Assignments were integrated into course-content 
lectures held once a week for 50 minutes throughout the 15-week semester. Groups of two to three students were provided an agricultural mentor who provided guidance on a semester-long research project. Cooperative Extension Educators $(n=5)$ were selected to participate in the program and serve as mentors.

Intercultural learning assignments and activities included: the Name Game (a culturally focused icebreaker), the I am poem (a self-awareness creative reflection), Alpha/Beta role play (simulation focusing on differences in cultural values and communication styles), and a local Asian market ethnographic visit (experiential activity) (Stringer and Cassiday, 2009). A written reflection from each student followed each assignment. The Thiagi Debrief questions guided the students through the reflective process (thiagi.com). Each activity was chosen to support self-awareness and awareness of others learning outcomes.

\section{Student Learning Assessment}

The BEVI was selected to assess student development. This instrument is a psychometric instrument used in analysis of individual and group learning experiences in a variety of contexts including higher education institutions, organizations, and international education (BEVI, 2018). The BEVI is a mixed methods instrument (demographics, 185 quantitative items, and 3 open-ended questions) that is administered online. Outputs from the assessment in the form of an individualized narrative report aim to aid users in better understanding their own and others' beliefs and values, and to encourage reflection on the implications of their value and belief systems for learning, relationships, and life experiences (Shealy, 2016). The BEVI has continuously developed since the nineties, supported both theoretically (relative to EI theory) and empirically (Shealy, 2016). The instrument has strong construct validity and reliability as reflected in Cronbach's Alpha calculations ranging by scale from 0.610 to 0.903 , and adequate model fit as demonstrated through confirmatory factor analysis that yielded CFIs above 0.9 and pvalues of 0.000 for all 17 scales (Wandschneider, et al., 2015).

The BEVI was selected due to the extensive breadth of analysis. Through a wide range of statistical procedures, it has been found repeatedly that BEVI questions cluster or group into specific factors or scales (BEVI, 2018). The instrument includes 7 domains that measure elements of the structure of the self (Shealy, 2005). These domains contain clusters of scales, 17 in all (Shealy, 2016). Table 1 includes further details about BEVI scales. This tool uses a broad, whole person approach, yet also provides a deep dive view into the ways in which individuals' experiences have shaped their beliefs and values and, importantly for this study, the ways in which individuals' beliefs and values impact learning. This assessment was administered in both week one (pretest, or T1) and week 15 (posttest, or T2) of the semester with $100 \%$ response rate $(n=11)$. All students completed the BEVI as a requirement for the course. Students received narrative reports of their individual results by email from BEVI and were debriefed as a group by a qualified BEVI administrator from Purdue's Center for Intercultural Learning, Mentorship, Assessment, and Research (CILMAR) on aggregate mean scores and distributions for various scales during a class session. Both of these formative assessments encouraged students to reflect on their identities and value systems, homogeneity and variation within the group, and their preparedness and motivations to engage in learning through the course of the program. 
Table 1. Course Intercultural Learning Outcomes, BEVI Structure, Scales, and Sample Items assessed in the current study.

\begin{tabular}{|c|c|c|c|c|c|}
\hline \multicolumn{2}{|c|}{$\begin{array}{c}\text { Course } \\
\text { Intercultural } \\
\text { Learning Outcomes }\end{array}$} & \multirow{2}{*}{\begin{tabular}{l}
\multicolumn{1}{c}{$\begin{array}{c}\text { BEVI } \\
\text { Domain }\end{array}$} \\
Formative \\
Variables
\end{tabular}} & \multirow{2}{*}{\begin{tabular}{l}
\multicolumn{1}{c}{ Scale } \\
Negative Life \\
Events
\end{tabular}} & \multirow{2}{*}{\begin{tabular}{l}
\multicolumn{1}{c}{ Description } \\
Difficult childhood; parents \\
were troubled; life \\
conflict/struggles; many \\
regrets
\end{tabular}} & \multirow[b]{2}{*}{$\begin{array}{l}\text { Sample Items } \\
\text { "I have had a lot of } \\
\text { conflict with one or } \\
\text { more members of } \\
\text { my family." } \\
\text { "My family had a } \\
\text { lot of problems } \\
\text { with money." }\end{array}$} \\
\hline 1) & $\begin{array}{l}\text { Identify Values } \\
\text { and beliefs and } \\
\text { determine how } \\
\text { they have } \\
\text { shaped their } \\
\text { own culture }\end{array}$ & & & & \\
\hline 2) & $\begin{array}{l}\text { Discuss the } \\
\text { differences in } \\
\text { common } \\
\text { agricultural } \\
\text { practices } \\
\text { between } \\
\text { cultures }\end{array}$ & $\begin{array}{l}\text { Fulfillment of } \\
\text { Core Needs }\end{array}$ & $\begin{array}{l}\text { Needs } \\
\text { Fulfillment }\end{array}$ & $\begin{array}{l}\text { Open to experiences, needs, } \\
\text { and feelings; deep } \\
\text { care/sensitivity for self, } \\
\text { others, and the larger world }\end{array}$ & $\begin{array}{l}\text { "We should spend } \\
\text { more money on } \\
\text { early education } \\
\text { programs for } \\
\text { children." } \\
\text { "I like to think } \\
\text { about who I am." }\end{array}$ \\
\hline 3) & $\begin{array}{l}\text { Identify cultural } \\
\text { differences and } \\
\text { process those } \\
\text { differences by } \\
\text { establishing } \\
\text { cross-cultural } \\
\text { ideas }\end{array}$ & Self Access & Meaning Quest & $\begin{array}{l}\text { Searching for meaning; } \\
\text { seeks balance in life; } \\
\text { resilient/persistent; } \\
\text { concerned for less fortunate }\end{array}$ & $\begin{array}{l}\text { "I think a lot about } \\
\text { the meaning of } \\
\text { life." } \\
\text { "I want to find a } \\
\text { better sense of } \\
\text { balance in my life." }\end{array}$ \\
\hline \multirow[t]{3}{*}{ 4) } & \multirow[t]{3}{*}{$\begin{array}{l}\text { Demonstrate } \\
\text { teamwork by } \\
\text { constructing a } \\
\text { solution to a } \\
\text { concern in the } \\
\text { visiting country }\end{array}$} & $\begin{array}{l}\text { Critical } \\
\text { Thinking }\end{array}$ & $\begin{array}{l}\text { Socioemotional } \\
\text { Convergence }\end{array}$ & $\begin{array}{l}\text { Open, thoughtful, } \\
\text { pragmatic, determined; sees } \\
\text { world in shades of gray }\end{array}$ & $\begin{array}{l}\text { "We should do } \\
\text { more to help those } \\
\text { who are less } \\
\text { fortunate." } \\
\text { "Too many people } \\
\text { don't meet their } \\
\text { responsibilities." }\end{array}$ \\
\hline & & Other Access & $\begin{array}{l}\text { Sociocultural } \\
\text { Openness }\end{array}$ & $\begin{array}{l}\text { Progressive/open regarding } \\
\text { a wide range of actions, } \\
\text { policies, and practices in the } \\
\text { areas of culture, economics, } \\
\text { education, environment, } \\
\text { gender/global relations, } \\
\text { politics }\end{array}$ & $\begin{array}{l}\text { "We should try to } \\
\text { understand } \\
\text { cultures that are } \\
\text { different from our } \\
\text { own." } \\
\text { "There is too big a } \\
\text { gap between the } \\
\text { rich and poor in } \\
\text { our country." }\end{array}$ \\
\hline & & Global Access & $\begin{array}{l}\text { Ecological } \\
\text { Resonance }\end{array}$ & $\begin{array}{l}\text { Deeply invested in } \\
\text { environmental/sustainability } \\
\text { issues; concerned about the } \\
\text { fate of the earth/natural } \\
\text { world }\end{array}$ & $\begin{array}{l}\text { "I worry about our } \\
\text { environment." } \\
\text { "We should protect } \\
\text { the land no matter } \\
\text { who owns it." }\end{array}$ \\
\hline
\end{tabular}

\section{Analysis}

As a holistic instrument, the BEVI is not meant to be analyzed by cherry-picking one or two scales from the seventeen. Because of the robust nature of the data which can be 
overwhelming to consider in its entirety, however, one common approach is to choose a subset of scales that align well with course learning outcomes. For purposes of this study, researchers analyzed six scales: three that correlated with learning outcomes for the courses and three that produced the largest unintended changes. These six scales are representative of the range of constructs measured by the BEVI, since they fall across six of the seven domains. Course learning outcomes included 1) identifying values and beliefs and determine how they have shaped their own culture; 2) recognizing differences in common agricultural practices between cultures; 3) demonstrating an understanding of culture, opportunities, and challenges in international agriculture as a means for improving ability to locally address global issues; and 4) demonstrating teamwork by constructing a solution to a concern in the visiting country (Table 1). Standard practice for BEVI score analysis, based on extensive empirical research support, is to assume meaningful differences in longitudinal change or between-groups difference at 5 points or more on the normed scales, which range from 1-100 (Iseminger et al., 2020). While this assumption does not guarantee statistical significance, it provides a way for BEVI administrators to interpret descriptive reports (means and distributions) automatically generated by the BEVI website without seeking special access to identifiable data (which could be ethically problematic for instructors and their current students) and conducting more sophisticated statistical analyses (a moot point with such a small N, anyway). With larger groups where such statistical analysis is possible, 5 points is still often used as a minimum change or difference indicative of real-world impact even when smaller differentials are statistically significant, because less than a $5 \%$ shift on a normed attitudinal scale is not likely observable. Such interpretative indicators of real-world meaning for psychometric instruments evolve over time from normative data and may vary across contexts (Fayers \& Hays, 2005).

The three scales related to course outcomes are 1) Sociocultural Openness, where high scores indicate willingness to consider other cultural worldviews and value systems, as well as willingness to interact with culturally different others; 2) Socioemotional Convergence, where high scores demonstrate consciousness of the self in relation to broader contexts, resulting in nuanced and complex understandings of events, people, and phenomena; and 3) Ecological Resonance, where high scores illustrate strong investment in environmental issues, connection to the natural world, and concerns regarding sustainability and the protection of natural resources (Wandschneider et al., 2015). Specific course outcomes and related scales are outlined in Table 1.

In addition, three further scales less explicitly connected to course outcomes were also analyzed because the T1 to T2 change was documented, although not deliberately sought: 1) Meaning Quest, where high scores are indicative of a tendency to deeply consider philosophical questions, to habitually search for higher meaning or purpose, and to seek balance and attunement; 2) Negative Life Events, where high scores reflect a traumatic upbringing or a childhood and youth full of physical/material challenges, psychological struggles, and/or conflict; and 3) Needs Fulfillment, where high scores suggest attention to one's needs, a commitment to self-care as well as caring for others, and a strong sense of self-efficacy (Wandschneider et al, 2015)(Table 1).

\section{Results}

While there was $100 \%$ response rate, one post-test administration was removed from analysis because it failed validity checks for the test administration. This removal 
occurs automatically in the report generation if low consistency or congruency scores manifest. Results presented include the remaining undergraduate participants $(n=10)$. Student demographics included 40.0\% $(n=4)$ male and $60.0 \%(n=6)$ female, $40.0 \%(n=4)$ first year, $20.0 \%(n=2)$ second year, $30.0 \%(n=3)$ third year, and $10.0 \%(n=1)$ fourth year. The group was representative of several majors, including Animal Sciences $(70.0 \% ; n=7)$, Agronomy (20.0\%; $n=2)$, and Agricultural Engineering (10\%; $n=1)$. The BEVI provides participant ethnic subcategories including Non-Caucasian and Caucasian in which our students represented $n=2$ and $n=8$ respectively.

Figure 1 (A-C).

Student results $(n=10)$ on three BEVI scales related to course learning outcomes ( $G=$ Group, M=Male, F=Female, $C=$ Caucasian, NC=Noncaucasian) before and after participating a study abroad program

* Meaningful differences are assumed at a longitudinal change or between-groups difference of 5 points or more on the normed scales (Shealy, 2016)

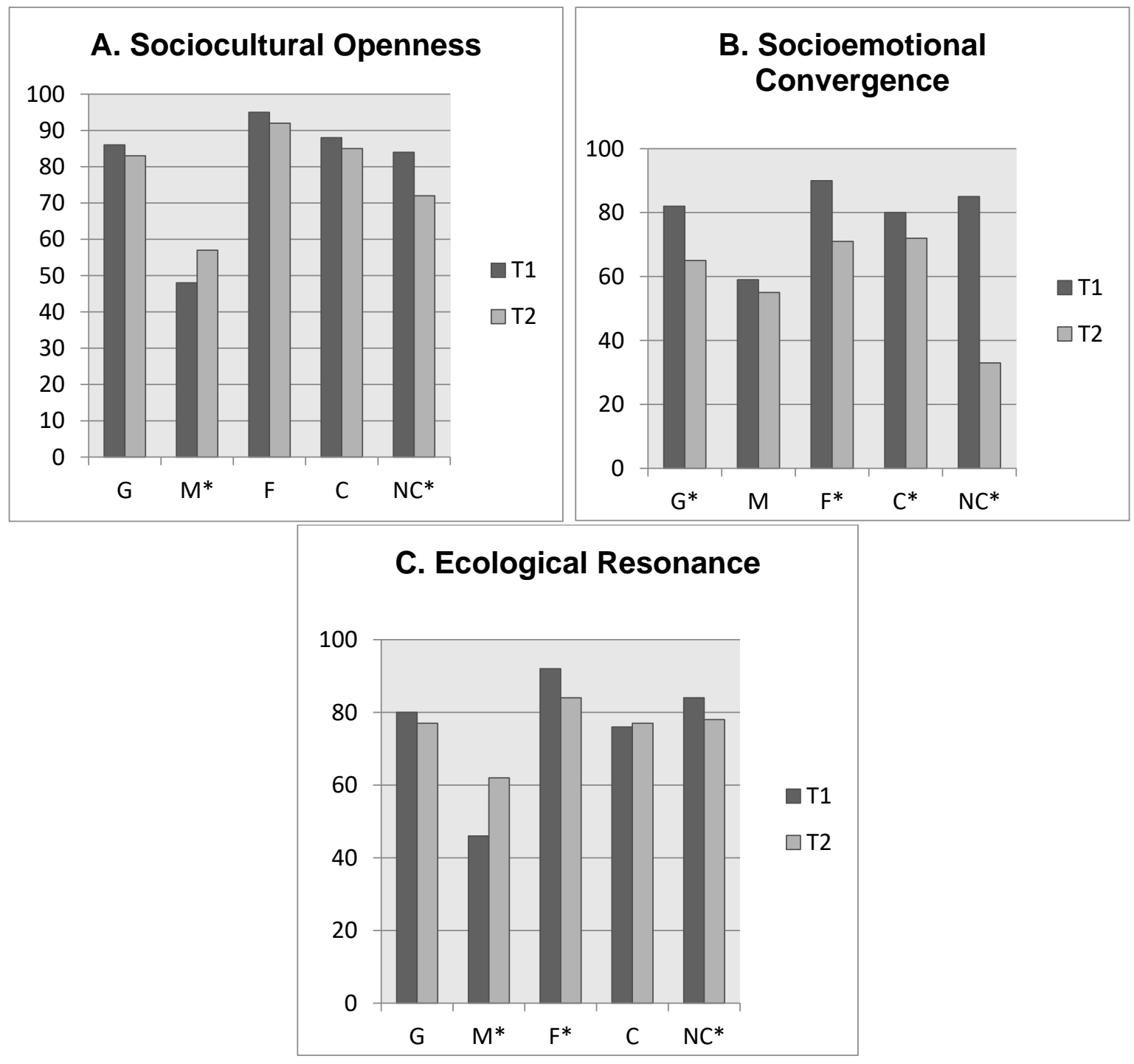


Real-world meaningful differences are assumed at a longitudinal change or between-groups difference of 5 points or more on the 100-point normed scales (Shealy, 2016). In lieu of statistical analysis (which in this case would not make sense given the small N), 5 point meaningful differences are often used to identify patterns in group and subgroup data (see Iseminger et al., 2020 for an example). As a group, Sociocultural Openness displayed no difference between T1 and T2 (Figure 1A). At the gender and ethnicity levels, however, differences emerged. Male participants' scores meaningfully increased (by 9 points). We see a meaningful decrease (by 12 points) for Non-Caucasian participants. In Socioemotional Convergence, we note a meaningful decrease (by 17 points) as a group from T1 to T2 (Figure 1B). Subgroup results indicate that all but the group of male participants displayed a meaningful decrease (female, 19 points; Caucasian, 8 points; Non-Caucasian, 52 points). Ecological Resonance displayed no meaningful change at the group level (Figure 1C). Results vary by gender and ethnicity variables. There is a meaningful increase (by 16 points) by male participants and decrease (by 8 points) by female participants from T1 to T2. Also, while Caucasian participants remained nearly the same, Non-Caucasian participants meaningfully decreased (by 6 points).

Figure 2 (A-C).

Student results $(n=10)$ on three BEVI scales with the most unintended change ( $G=$ Group, $M=$ Male, F=Female, $C=$ Caucasian, NC=Noncaucasian) before and after participating a study abroad program.

* Meaningful differences are assumed at a longitudinal change or between groups difference of 5 points or higher on the normed scales (Shealy, 2016).

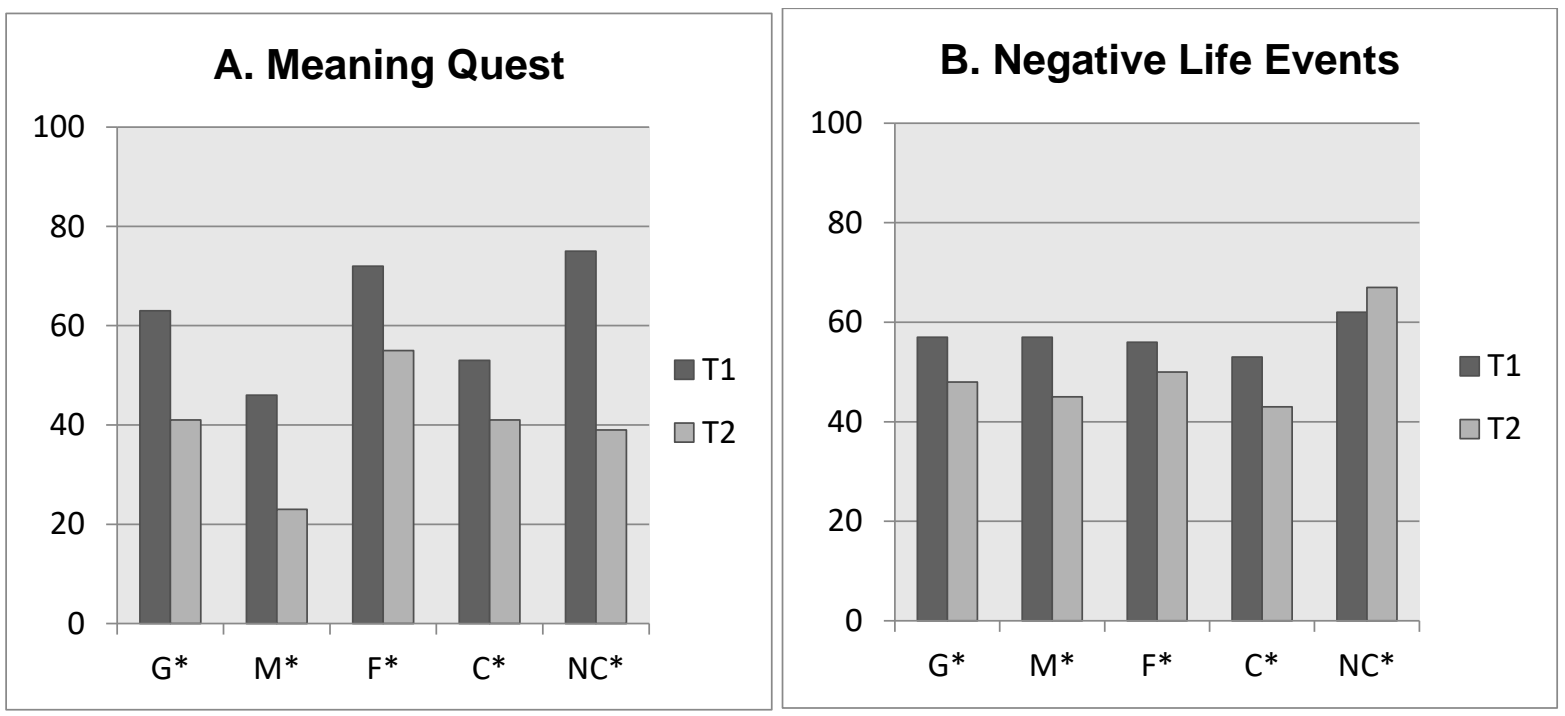




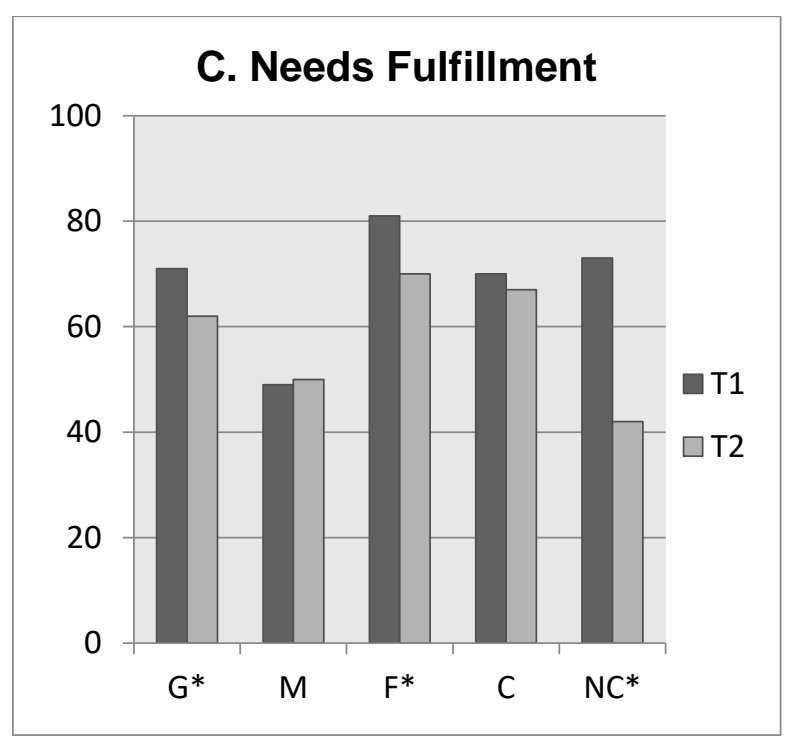

Although not intended, and not linked to course learning outcomes at the start of the course, we identified three additional scales that exhibited meaningful differences in our student population. The Meaning Quest scale displayed changes from the group, gender, and ethnic levels (Figure 2A). As a group, participants decreased 22 points. Reflected in the group average, both male and female decreased (Male, 23 points; Female, 17 points), and both Caucasian and Non-Caucasian participants meaningfully decreased (Caucasian, 12 points; Non-Caucasian, 36 points). The Negative Life Events scale is a Formative Variable. Group results show a meaningful decrease from T1 to T2 (9 points) (Figure 2B). The male and female groups and Caucasian group of participants showed meaningful decreases (Male, 12 points; Female, 6 points; Caucasian, 10 points). NonCaucasian participants meaningfully increased (by 5 points). The Needs Fulfillment scale, within the Fulfillment of Core Needs domain, displayed a meaningful decrease (by 9 points) as a group (Figure 2C). The program's female and Non-Caucasian subgroups both decreased (Female, 11 points; Noncaucasian, 31 points).

Quantitative results can be broken down into deciles. Deciles show the spread of participants across the T1 and T2 time points and are crucial for understanding group distribution (Table 2). It is clear with Negative Life Events that there was a shift from the polar ends ( 1 and 10, containing $36 \%$ in each decile at T1) towards the middle, but most movement was from the highest (10) by $16 \%$ down the scale (Table 2). These patterns of score shifts indicate changing interpretations of childhood experiences in light of the SA experience, with very positive T1 perceptions growing slightly more negative in $\mathrm{T} 2$ and very negative $\mathrm{T} 1$ evaluations of early childhood becoming slightly more positive. Those with Needs Fulfillment scores in the lowest decile (containing 29\% of the participants) increased their fulfillment of needs, but students in the highest decile (36\%) shifted down by $26 \%$. This scale also displays a less polarized spread - a flatter distribution of the course participants. Socioemotional Convergence indicates a similar pattern. Students in the lowest bracket (29\%) developed over the course of the semester, increasing on the scale, leaving no participants in the first two deciles. Students in the highest deciles decreased, indicating that $40 \%$ of participants regressed towards less critical thinking.

Participants were polarized in their position on the Meaning Quest scale $(29 \%$ of students in decile 1 and $26 \%$ in decile 10) (Table 2). The lowest deciles indicate more 
pragmatic thinking while the high end indicates a more philosophical thinking process. Participants on the highest end predominately shifted towards a more pragmatic view (decreasing by 36\%) over the course of the semester. In Sociocultural Openness, there was little movement from participants on the highest end of the scale (decreasing 10\%), but a large shift is present from the lowest end of the scale (increasing 29\%). Lastly, those who were at the low end of Ecological Resonance moved further towards the middle (by increasing 21\%), while those on the highest end moved down (by 30\%). The spread shifted to the higher end following program participation.

\section{Table 2. Student participant $(n=10)$ spread across 6 Beliefs, Events, and Values Inventory (BEVI) scales.}

\begin{tabular}{|c|c|c|c|c|c|c|c|c|c|c|c|}
\hline & Deciles: & 1 & 2 & 3 & 4 & 5 & 6 & 7 & 8 & 9 & 10 \\
\hline \multirow{2}{*}{$\begin{array}{l}\text { Negative Life } \\
\text { Events }\end{array}$} & $\mathrm{T} 1$ & 36 & 7 & 0 & 0 & 0 & 7 & 0 & 14 & 0 & 36 \\
\hline & $\mathrm{T} 2$ & 30 & 0 & 0 & 0 & 20 & 20 & 0 & 10 & 0 & 20 \\
\hline \multirow{2}{*}{$\begin{array}{l}\text { Needs } \\
\text { Fulfillment }\end{array}$} & T1 & 29 & 0 & 7 & 0 & 0 & 7 & 0 & 7 & 14 & 36 \\
\hline & $\mathrm{T} 2$ & 0 & 0 & 0 & 20 & 20 & 10 & 10 & 10 & 20 & 10 \\
\hline \multirow{2}{*}{$\begin{array}{l}\text { Socioemotional } \\
\text { Convergence }\end{array}$} & T1 & 29 & 0 & 0 & 0 & 0 & 0 & 7 & 7 & 7 & 50 \\
\hline & $\mathrm{T} 2$ & 0 & 0 & 20 & 10 & 0 & 10 & 10 & 10 & 30 & 10 \\
\hline \multirow[t]{2}{*}{ Meaning Quest } & $\mathrm{T} 1$ & 29 & 7 & 7 & 0 & 7 & 0 & 0 & 7 & 7 & 36 \\
\hline & $\mathrm{T} 2$ & 20 & 0 & 10 & 20 & 10 & 10 & 10 & 10 & 10 & 0 \\
\hline \multirow{2}{*}{$\begin{array}{l}\text { Sociocultural } \\
\text { Openness }\end{array}$} & T1 & 29 & 0 & 0 & 0 & 7 & 0 & 7 & 0 & 7 & 50 \\
\hline & $\mathrm{T} 2$ & 0 & 0 & 0 & 0 & 20 & 10 & 10 & 10 & 10 & 40 \\
\hline \multirow{2}{*}{$\begin{array}{l}\text { Ecological } \\
\text { Resonance }\end{array}$} & T1 & 21 & 0 & 0 & 14 & 7 & 7 & 0 & 0 & 0 & 50 \\
\hline & $\mathrm{T} 2$ & 0 & 0 & 10 & 10 & 10 & 0 & 0 & 30 & 20 & 20 \\
\hline
\end{tabular}

Note. Each square in Table 2 represents the percentage of students within that decile range on each respective scale. T1 represents results at time point 1 and T2 represents results at time point 2 .

Participants in the course also responded to three open-ended BEVI prompts (Table 3). Taken together, these representative quotes highlight an increase in cultural selfawareness, awareness of other cultures, and openness.

\section{Table 3. Representative statements from participants completing the open-ended BEVI prompts at the end of the program.}

Please describe which aspect of this experience has had the greatest impact upon you.

Students "I really enjoyed staying in the mountains. It submerged me in the culture and the atmosphere."

"Witnessing the poverty and different cultures for the first time in my life."

"Being able to see first-hand the high language barrier and how difficult it can be to communicate with people. I had never had to communicate with someone who didn't speak the same language as me, so this was impactful in showing me how challenging it can be."

Is there some aspect of your own 'self' or "identity" that has become clear or relevant as a result of this experience?

Students "I realized how fortunate I am to have what I have."

"I learned how important people's feelings and beliefs mean to me."

"I think the whole trip really helped with self-identity and showed me what I like and don't like and how my personality and overall being was effected by it."

What are you learning or how are you different as a result of this experience?

Students "I should appreciate the things that I have in life, because many people around the world live in very dire economic and political situations."

"I have learned about self-identity and who I want to be."

"I learned more about the issues that have occurred in the past for other ethnicity and that has helped me respect them more and understand their culture more." 


\section{Discussion}

This study examined Sociocultural Openness, Socioemotional Convergence, and Ecological Resonance in ten students participating in a SA program. Little to no overall gains were observed on these scales. For Sociocultural Openness and Ecological Resonance, a lack of growth in the group aggregate scores is not surprising because of the initial high T1 scores; there was very little room to grow on a normed scale from 1-100 at 86 and 80, respectively. Baseline reports indicate that students were advanced in comparison to other students at a large, STEM, predominately white institution, who had scores of 66 in Sociocultural Openness and 62 in Ecological Resonance (Wandschneider et al., 2015). High scores on these scales may be due to students' self-selection into a SA program of this nature, choosing to participate because they held these values. There was no meaningful change, indicating the group remained high in a willingness to be open to differences and in investment in environmental issues. Socioemotional Convergence decreased meaningfully over the course of the semester. Again, this result is not unusual for educational courses or programs that provide opportunities for learners to encounter significant cultural differences (Acheson \& Schneider-Bean, 2019). Overstimulation and instability can be caused by the overwhelming experience of being in a foreign environment (Stuart, 2012) and coping responses to these stresses are sometimes expressed as regressions on intercultural assessments (Snodgrass et al., 2018).

Unintended change among this group were meaningful downward shifts on scales Meaning Quest, Negative Life Events, and Needs Fulfillment. A decrease in Meaning Quest indicates that participants valued less philosophical analysis or believed that searching for the purpose in life was less of a priority following participation in this course. A decrease in Needs Fulfillment indicates that following participation in the program, as compared to the beginning of the program, learners felt less self-efficacy and more of their needs were unmet. These results, although not anticipated by course leaders, can be explained by the normal, and potentially short-term, reactions of students to the physical and psychological stresses of cultural adaptation (Wandschneider et al., 2015). Decrease presented on the Negative Life Events scale could be considered a positive outcome, as it indicates that student participants had altered their perception of the events and challenges encountered throughout their upbringing, finding them less traumatic after having experienced life in a different cultural context. However, Non-Caucasian participants had a starkly different response on the Negative Life Events scale by increasing meaningfully. This is a small sample $(n=2)$ which cannot be generalized to other similar students. Students from different identity groups have different experiences abroad; realization of minority status can heighten awareness of students' identity within the group and can cause further stress (Savicki \& Cooley, 2011). The destination of Vietnam, a developing country vastly different from the United States, provides a contrasting perspective, which enables increased cognitive dissonance resulting in the current data (Lee \& Negrelli, 2018).

Forming new beliefs and values is not a simple procedure. EI theory describes the foundation of our beliefs and values system as a strong, well-developed structure (Shealy, 2016). In order to replace an existing portion of this structure, breaking down of the building blocks of that structure is necessary. Reforming this foundation takes time, so while students in this study decreased across many of the scales discussed here, it is expected that with sufficient time to process that BEVI scores will not only recover, but surpass their original scores (Wandschneider et al., 2015). 
Gender differences highlighted in the data align with previous research. Students in this cohort were higher to begin with than baseline BEVI reports from a large university on Sociocultural Openness, Socioemotional Convergence, and Ecological Resonance (Shealy, 2016). However, our study is a small sample from a large university. The differences between the male and female subgroups represent typical differences present between genders (Shealy, 2016). Both male and female students demonstrated having similar beliefs about their Negative Life Events. Multiple variations exist between male and female experiences throughout SA programs (Wielkiewicz \& Turkowski, 2010). SA provides a new environment and cultural interactions that can produce stress and anxiety among students (Dewey et al., 2018). These stressful situations can generate emotional responses and gender roles and expectations can influence emotional responses and expressivity (Deng et al., 2016). Gender differences, however, depend on the emotion experienced. Emotions that can be encountered throughout the duration of study abroad participation can include shame/guilt, and frustration/disappointment (Laliberté \& Waddell, 2017).

Disparate outcomes, both at the start and end of the semester, between gender and ethnicity indicate that individual needs of support vary between students as influenced by the intersectionality of their identities. Furthermore, Dewey et al. (2018) indicates that stress among students during SA programs can be compared to major life stressors that can inhibit learning and be considered debilitating. Stress can be induced upon return from SA as well, including potential changes in relationships and skepticism of the home culture (Wielkiewicz \& Turkowski, 2010). Stressors are cognitively and emotionally burdening, requiring sufficient time to allow students to process the cognitive dissonance they experience during encounters (Snodgrass et al., 2018).

Students challenged with the experiences provided in intercultural learning experiences benefit from formative assessment emphasizing affective behavior (Iyer, 2013). Gains in content knowledge, while a critical SA component, are inhibited if students are not affectively supported or prepared; students with lower affective stability, or less emotional coping strategies, have a harder time adjusting to situations abroad, including poorer psychological adjustments and behavioral performances (Savicki, 2013). In addition, students racial, ethnic, and gender identities intersect and can each affect their experience studying in STEM disciplines (Brown, 2016). Providing an outlet for students to make sense of their identities and the complexity of those identities is a successful means of student support (Lonsdale, 2015). In addition to intercultural learning activities, traveling abroad, and discipline content, emotional support is required. In science majors, technical skills cannot be the only skills developed; understanding people's multidimensional identities and their interactions with science must become a priority (Rahm, 2016).

Differences between gender and ethnicity, in addition to the vast array of student positionality on scales analyzed in this study, inform program leaders about the preparedness of students to engage in cross-cultural learning. For example, at T1, 29\% of participants in this study were in the lowest decile of Sociocultural Openness, meaning that 3 of 10 participants were extremely hesitant to interact with culturally different others and unwilling to consider alternate viewpoints as valid. Preparedness in this case is an obstacle to learning. Students farthest from the learning outcomes of the course, with the most growth to achieve, have the least capacity to respond to challenging experiences in ways that support growth. In a SA program, to expect a prepared participant to hold this value and belief is realistic. However, participants are each unique and hold different 
worldviews. In that sense, the response of these "most-in-need" students to the program in this study is encouraging. Even when overall group aggregates did not change on the Needs Fulfillment, Sociocultural Openness, and Ecological Resonance scales, the students in the 1st decile (farthest from the desired learning outcome) grew the most.

Using assessments, such as the BEVI, practitioners can analyze preparedness of the group and use results to enhance student learning (Earl, 2003). Material tailored to student experience level aids in ensuring a better learning outcome because they are more useful for students (Guskey, 2003). Additionally, formative assessments can provide valuable information about what is effective or not, which can be valuable in preparation for SA programs. Further analysis of course reflections may yield insight into the specific effects of identity components at different time points throughout the semester. Formative assessments, such as the BEVI, can be valuable assets in the classroom (Earl, 2003; Guskey, 2003).

Beliefs and values are constructed through processes over long periods of time, creating a complex network that creates the foundation of an individual (Shealy, 2016). This foundation influences the framework used to make sense of experience, which in turn influences students' interactions with cultural differences. Results from this small sample indicate a variety of responses to student experiences in a SA program. Group dynamics (i.e., the spread in beliefs in values) influence aggregate scale means, and without further evaluating subgroups or decile data, a different story is portrayed. Group data display a polarized participant pool at the beginning of the program. Analyzing beyond group averages provides educators and researchers a more holistic view of their participant pool (Wandschneider et al., 2015; Krishnan et al., 2017).

\section{Conclusions}

Intercultural competence is a vital skill and learning outcome associated with many SA programs. Fostering the skills needed for global citizenship in undergraduate students is imperative to prepare students for not only the workplace, but to assist them in navigating a rapidly changing society in the US. Many of our students are living in a world experiencing the negative impacts of a global pandemic and a country that is desperately looking for solutions to racial injustice and the dealing with the consequence of political division. Developing the skills needed for cultural self-awareness, awareness of others, and intercultural communication skills, is absolutely critical during these turbulent times.

Formative and summative assessment is essential in monitoring the development of intercultural competence, including before, during, and after international travel. As both a formative and summative assessment tool, the BEVI provides a unique perspective of cohort composition of beliefs and values. One advantage of using this tool is that the T1 data provide not only a baseline for comparison with later posttest data but also an opportunity for instructors to better know their students and for learners to better know themselves going into a stressful cultural transition. Even if changes to planned curricula are not made as a result of T1 analysis and discussion, the resulting understanding of students' beliefs and values informs many dimensions of instructor support for student learning, for example the ways in which they guide intercultural activity debriefings and their responses to students in moments of crisis while traveling. Even in the current times of limited mobility, this type of assessment has value for learners who are interacting across difference in the local communities or via virtual classroom experiences. 
BEVI results highlight student individuality, preparedness of students to interact cross-culturally, and program effectiveness and ineffectiveness in meeting course learning outcomes. The T1 debriefing with students emphasized that the group was not homogenous with regard to preparedness, a fact which became increasingly clear during the nine days in Vietnam when students reacted differently to events and cultural phenomena. T2 analysis also sheds light on what students took away from (or didn't) from those experiences abroad in a complex interaction between who they were and to what extent they achieved intended learning outcomes. The noble goal of creating global citizens through SA is multidimensional and not an easy task to accomplish. Strategic implementation of support to complement intercultural learning is necessary for success.

\section{Limitations}

Limitations in this study include a small, self-selected sample of learners that is an effective case study but is difficult to generalize to other programs. The $\mathrm{N}$ of 10 students limited analysis options to comparison of means and mean differences since t-tests and other more sophisticated statistical analyses would not have yielded significant results. This was also a single group study with no comparison group, meaning that changes between T1 and T2 are not clear evidence of causality. While these limitations result in quantitative data that are not generalizable beyond this particular group of students, these data still provide valid and insightful information about the group itself, as well as the individual members of the group. The approach models how a quantitative or mixed methods measure can be effectively employed even with a very small number of participants. Another less than ideal program feature in this case was that the researchers had limited contact with participants after the completion of the semester program, inhibiting the ability to conduct a delayed posttest or T3 assessment; longitudinal data of this kind would have been advantageous to track longer-term program impacts such as continued growth or attrition of learning. Although such limitations are common in SA research because of logistical constraints, they should be addressed in future research in order to strengthen conclusions and the transferability of implications to other programs.

A further limitation of the study lies in the lack of course design responsiveness to formative assessment. In this case, the learners themselves benefited from the formative assessment using the BEVI, in the form of both individual and group feedback from the instrument, as they prepared for the embedded SA to Vietnam. Moreover, the instructors and mentors were able to get a sense of who the students were before spending time abroad with the group, with this knowledge informing the ways in which they challenged and supported learners in situ. The fact that the course was not significantly updated or differentiated in terms of content or teaching strategies in response to this formative assessment, however, constitutes a pedagogical missed opportunity.

Finally, best practices in assessment of learning outcomes include "closing the loop" on assessment cycles in an iterative approach to course design, which requires instructors to reflect on the effectiveness of the pedagogical choices they made and note areas for potential change or improvement next time the experience is offered to another cohort of learners. After analyzing this BEVI data, the instructors intend to utilize information gained from the BEVI in future cohorts to create activities and a learning environment that will be most beneficial for the students and support intercultural development. 


\section{Implications}

This study has provided several implications for potential application in similar SA programs. These implications are categorized in two themes: 1) the individualized student and 2) criticality of assessment aligned with learning outcomes.

1A) Instructors must first and foremost understand who their SA participants are in order to design effective curriculum and support. Students start at varying levels and each come into a program holding unique values and beliefs shaped from their life experiences. Incorporating the BEVI at the start of a program may provide the instructors with insight to adapt assessment and discussions throughout the duration of the program to better meet the defined student learning outcomes for individual students. As illustrated here, quantitative tools can be effective for this purpose even with a small $\mathrm{N}$.

1B) Additionally, a critical component of understanding student participants is recognizing the intersectionality of identities each student possesses and how the multidimensional nature of identity influences their worldview. Students vary in gender, ethnicity, and educational, or travel, experience, and background; these variations require differences in support levels. Formative assessment such as a debriefing of BEVI group results is key to recognizing the diversity present in a group of students and subsequently differentiating instruction appropriately. An advantage of the BEVI here is its capacity for subgroup and decile analyses in addition to the more typical look at whole group means.

1C) The BEVI is a validated and reliable assessment tool that highlights students' beliefs and values, informing study abroad instructors of participant preparedness to interact in a different culture. Without the right support, backlash may ensue and result in students not attaining, or moving farther from, course learning outcomes. With formative assessment such as reflection on individual narrative reports, students themselves can become more aware of their preparedness and proactively work towards resilience and growth. In this way, assessment becomes an essential part of the course experience rather than simply a source of information for instructors.

2A) Formative assessment in behavior, emotional, and other affective levels associated with learning outcomes is pertinent to student learning. Affective experiences can help or hinder what students are retaining from cognitive learning goals. Course design should reflect not only the knowledge and skills, but additionally, the attitudes needed to meet course learning outcomes. The BEVI focuses attention on the affective domain so often missing in higher education, which tends to concentrate on cognitive outcomes and the transfer of knowledge.

2B) Holistic instruments such as the BEVI offer the potential to document learning outcomes and areas of development and/or struggle that may not have been intended outcomes of the learning intervention and thus would otherwise escape notice. While the messiness of rich data sets such as the BEVI is a challenge, the potential to uncover insights researchers may not have been deliberately seeking is invaluable.

\section{References}

Acheson, K., and S. Schneider-Bean. (2019). Representing the intercultural development continuum as a pendulum: Addressing the lived experiences of intercultural competence development and maintenance. European Journal of Cross-Cultural Competence and Management, 5(1), 42. 
Acheson, K., Dirkx, J., Wiley, J., Ullum, C., Kapadia, S., and Bhuyan, D. (in press, 2021). Operationalizing transformation of the self in high impact learning: Methodological considerations. In C. Shealy (Ed.), The Globally Sustainable Self. Oxford University Press.

Acheson, K., Dirkx, J., and Shealy, C. (2020). Assessing transformative learning. In E. Kostara, A. Gavrielatos, and D. Loads (Eds.), Transformative learning theory and praxis: New perspectives and possibilities. Taylor and Francis.

Acheson, K, Finley, A., Hickman, L., Sternberger, L., and Shealy, C. (2020). Formative, adaptable, and interdisciplinary innovations in assessment: Beliefs, Events, and, Values Inventory (BEVI), VALUE Rubrics, and Cultural Controllability Scale (CCS). In S. A. Nolan, C. Hakala, \& R. E. Landrum (Eds.), Assessment: Individual, institutional, and international approaches. Washington, DC: American Psychological Association.

Bedenlier, S., Kondakci, Y. and Zawacki-Richter, O. (2018). Two Decades of Research Into the Internationalization of Higher Education: Major Themes in the Journal of Studies in International Education (1997-2016). Journal of Studies in International Education, 22(2), 108-135. https://doi.org/10.1177/1028315317710093

The Beliefs, Events, and Values Inventory (BEVI). Retrieved December 11, 2020, from http://thebevi.com/about/scales/

Brown, B. (2016). A case study analysis of minority students' negotiation of STEM, racial/ethnic, and graduate student identities. ProQuest Dissertations \& Theses.

Byker, E. J., and Putman, S. M. (2019). Catalyzing Cultural and Global Competencies: Engaging Preservice Teachers in Study Abroad to Expand the Agency of Citizenship. Journal of Studies in International Education, 23(1), 84-105. https://doi.org/10.1177/1028315318814559

Cranton, P., and Taylor, E. W. (2012). Transformative learning theory: Seeking a more unified theory. In E. W. Taylor \& P. Cranton (Eds.), Handbook of transformative learning: Theory, research, and practice, 1st edition (pp. 3-20). Hoboken, NJ: John Wiley \& Sons.

Deng, Y., Chang, L., Yang, M., Huo, M., and Zhou, R. (2016). Gender Differences in Emotional Response: Inconsistency between Experience and Expressivity. PLOS ONE, 11(6), e0158666. https://doi.org/10.1371/journal.pone.0158666

Dewey, D. P., Belnap, R. K., and Steffen, P. (2018). Anxiety: Stress, Foreign Language Classroom Anxiety, and Enjoyment During Study Abroad in Amman, Jordan. Annual Review of Applied Linguistics, 38, 140-161. https://doi.org/10.1017/S0267190518000107.

Dixson, D., and Worrell, F. (2016). Formative and Summative Assessment in the Classroom. Theory Into Practice, 55(2), 0-14.

Earl, L. M. (2003). Assessment as learning: Using classroom assessment to maximise student learning. Thousand Oaks: Corwin Press.

Fayers, P., and Hays, R. (2005). Assessing quality of life in clinical trials: Methods and practice, $2^{\text {nd }}$ edition. Oxford University Press.

Freire, P. (1970). Pedagogy of the oppressed. New York: Seabury Press.

Guskey, T. R. (2003). How classroom assessments improve learning. Educational Leadership, 60(5), 6-11.

Hoggan, C. (2016). Transformative learning as metatheory: Definition, criteria, and typology. Adult Education Quarterly, 66(1), 57-75.

Iseminger, S., Acheson, K., Kelly, C., \& Morris, P. (2020). The effects of social identities on student learning outcome attainment. International Journal of Scholarship of Teaching and Learning, 14(1), Article 12, 1-13.

Iyer, C. (2013). Assessing and engaging beliefs and values in a learning community of U.S. and international students: Implications and applications from the Forum BEVI Project. (Unpublished doctoral dissertation). James Madison University, Harrisonburg, VA.

Kahn, H. E., and Agnew, M. (2017). Global Learning Through Difference: Considerations for Teaching, Learning, and the Internationalization of Higher Education. Journal of Studies in International Education, 21(1), 52-64. https://doi.org/10.1177/1028315315622022

Krishnan, L. A., Masters, C., Calahan, C., and Holgate, H. (2017). Structured Study Abroad Enhances Intercultural Competence. Teaching and Learning in Communication Sciences \& Disorders, 1(1). https://doi.org/10.30707/TLCSD1.1Krishnan

Kuh, G. D. (2008). High impact educational practices: What they are, who has access to them and why they matter. Washington, DC: Association of American Colleges and Universities. 
Laliberté, N., and Waddell, C. (2017). Feeling Our Way: Emotions and the Politics of Global Citizenship in Study Abroad Programming. Frontiers: The Interdisciplinary Journal of Study Abroad, 29(2), 79-93.

Lee, J., and K. Negrelli. (2018). Cultural identification, acculturation, and academic experience abroad: A case of a joint faculty-led short-term study abroad program. Journal of International Students, 8(2): 1152-1072. DOI: 10.5281/zenodo.1250417

Lilley, K., Barker, M., Harris, N. (2017). The Global Citizen Conceptualized: Accommodating Ambiguity. Journal of Studies in International Education, 21(1), 6-21. https://doi.org/10.1177/1028315316637354

Lonsdale, C. (2015). Engaging the "Othered": Using Zines to Support Student Identities. Language Arts Journal of Michigan, 30(2), 7-16.

Mawer, M. (2017). Approaches to Analyzing the Outcomes of International Scholarship Programs for Higher Education. Journal of Studies in International Education, 21(3), 230-245. https://doi.org/10.1177/1028315316687009

Mezirow, J. (1978). Perspective transformation. Adult Education, 28, 100-110.

Passarelli, A. M. and Kolb, D. A. (2012). Using experiential learning theory to promote student learning and development in programs of education abroad. In M. Vande Berg, R.M. Paige, and K.H. Lou (Eds.), Student Learning Abroad (Ch. 6, pp. 137-161). Sterling, VA: Stylus Publishing.

Purdue University Office of the Provost (2019). Expected Outcomes. Retrieved from https://www.purdue.edu/provost/students/s-initiatives/curriculum/outcomes.html

Rahm, J. (2016). Stories of learning, identity, navigations and boundary crossings in STEM in nondominant communities: New imaginaries for research and action. Cultural Studies of Science Education, 11(1), 61-75.

Roy, P., Wandschneider, E., and Steglitz, I. (2014). Assessing Education Abroad Outcomes: A Review of the BEVI, IDI, and GPI. White Paper. East Lansing: Michigan State University Office of Study Abroad.

Savicki, V. and Cooley, E. (2011). American Identity in Study Abroad Students: Contrasts, Changes, Correlates. Journal of College Student Development 52(3), 339-349.

Savicki, V. (2013). The Effects of Affect on Study Abroad Students. Frontiers: The Interdisciplinary Journal of Study Abroad, 22, 131-147.

Savicki, V., Brewer, E., Whalen, B., and EBSCOhost. (2015). Assessing study abroad: Theory, tools, and practice (First ed.). Sterling, VA: Stylus.

Shealy, C. N. (2004). A model and method for "making” a Combined-Integrated psychologist: Equilintegration (EI) Theory and the Beliefs, Events, and Values Inventory (BEVI). Journal of Clinical Psychology, 60(10), 1065-1090. https://doi.org/10.1002/jclp.20035

Shealy, C. N. (2005). Justifying the Justification Hypothesis: Scientific-humanism, Equilintegration (EI) Theory, and the Beliefs, Events, and Values Inventory (BEVI). Journal of Clinical Psychology, 61(1), 81106. https://doi.org/10.1002/jclp.20092

Shealy, C. N. (Ed.). (2016). Making sense of beliefs and values: theory, research, and practice. New York: Springer Publishing Company.

Snodgrass, L. L., Morris, P., and Acheson, K. (2018). Assessing the intercultural sensitivity of students in an agriculture diversity and social justice course. Multicultural Education Review, 10(4), 292-309. https://doi.org/10.1080/2005615X.2018.1532711

Stringer, D. M. and Cassiday, P. A. (2009). 52 activities for improving cross-cultural communication. Boston: Intercultural Press.

Stringfield, S., Stone, J. R. (2017). The Labor Market Imperative for CTE: Changes and Challenges for the 21st Century. Peabody Journal of Education, 92(2), 166-179. https://doi.org/10.1080/0161956X.2017.1302209

Stuart, D.K. (2012). Taking stage development theory seriously, implications for study abroad. In M. Vande Berg, R.M. Paige, and K.H. Lou (Eds.), Student Learning Abroad (Ch. 3, pp. 61-89). Sterling, VA: Stylus Publishing.

United States Department of Labor (USDOL). (2017). Women's Bureau. Data and Statistics. Retrieved from https://www.dol.gov/wb/stats/stats data.htm

University of Illinois Office of the Provost (2019). Illinois Student Learning Outcomes. Retrieved at https://provost.illinois.edu/assessment/learning-outcomes-assessment/illinois-student-learningoutcomes/

Vande Berg, M., Paige, R. M. and Hemming Lou, K. (Eds.). (2012). Student learning abroad: what our students are learning, what they're not, and what we can do about it (1. ed). Sterling, Va: Stylus Publ. 
Wandschneider, E., Pysarchik, D. T., Sternberger, L. G., Ma, W., Acheson, K., Baltensperger, B., Good, R.T., Brubaker, B., Baldwin, T. Nishitani, H., Wang, F. Reisweber, J., and Hart, V. (2015). The Forum BEVI Project: Applications and Implications for International, Multicultural, and Transformative Learning. Frontiers: The Interdisciplinary Journal of Study Abroad, 25, 150-228.

Wielkiewicz, R. M. and Turkowski, L. W. (2010). Reentry Issues Upon Returning From Study Abroad Programs. Journal of College Student Development 51(6), 649-664.

\section{Author Biographies}

Jacie Grant is the BOSC (Business Operations \& Supply Chain) Training Lead at Cargill, Dayton, VA. She completed both her undergraduate and master's degrees in Animal Sciences from Purdue University. Her background in cultural communication, international studies, and travel provided a foundation for her master's degree in intercultural learning through study abroad programs. Jacie's food production background and master's research are highly valuable in her leadership role onboarding, engaging, and retaining employees at the production facility as well as building local, community relationships and partnerships.

Dr. Kris Acheson is Director of Purdue University's Center for Intercultural Learning, Mentorship, Assessment and Research with a courtesy faculty appointment in the Brian Lamb School of Communication. A former US Fulbright Scholar (Honduras, 2015), she has 17 years of classroom teaching experience in intercultural communication, language instruction, and teacher training and has published extensively on the development and assessment of intercultural competence.

Dr. Elizabeth Karcher is an Associate Professor in Animal Sciences and is the Undergraduate Programs Coordinator for the department. She teaches a variety of courses and has developed study abroad programs on animal production and environmental challenges in Europe and Asia. Her research focuses on the development of innovative experiential learning platforms to enhance student learning. 